\title{
Bi-directional 120 km long-reach PON link based on distributed Raman amplification
}

\author{
Kjær, Rasmus; Tafur Monroy, Idelfonso; Oxenløwe, Leif Katsuo; Jeppesen, Palle
}

Published in:

IEEE Lasers and Electro-Optics Society annual Meeting

Link to article, DOI:

10.1109/LEOS.2006.278926

Publication date:

2006

Document Version

Publisher's PDF, also known as Version of record

Link back to DTU Orbit

Citation (APA):

Kjær, R., Tafur Monroy, I., Oxenløwe, L. K., \& Jeppesen, P. (2006). Bi-directional 120 km long-reach PON link based on distributed Raman amplification. In IEEE Lasers and Electro-Optics Society annual Meeting (pp.

WEE3). IEEE. https://doi.org/10.1109/LEOS.2006.278926

\section{General rights}

Copyright and moral rights for the publications made accessible in the public portal are retained by the authors and/or other copyright owners and it is a condition of accessing publications that users recognise and abide by the legal requirements associated with these rights.

- Users may download and print one copy of any publication from the public portal for the purpose of private study or research.

- You may not further distribute the material or use it for any profit-making activity or commercial gain

- You may freely distribute the URL identifying the publication in the public portal 


\section{Bi-directional 120 km Long-Reach PON Link Based on Distributed Raman Amplification}

\author{
COM•DTU, DTU, Ørsteds Plads 345V, \\ 2800 Kgs. Lyngby, Denmark \\ E-mail: rkj@com.dtu.dk
}

Rasmus Kjær, Idelfonso Tafur Monroy, Leif K. Oxenløwe and Palle Jeppesen

\author{
Bera Palsdottir \\ OFS Fitel Denmark, Priorparken 680, \\ 2605 Brøndby, Denmark
}

\begin{abstract}
We propose and demonstrate a bidirectional PON link with $120 \mathrm{~km}$ reach and symmetric up and down stream data rate of $10 \mathrm{Gbit} / \mathrm{s}$. Lossless transmission was achieved with $>40$ dB of received OSNR.
\end{abstract}

\section{INTRODUCTION}

Long reach access networks have been proposed as a promising way to reduce the unit cost of bandwidth in fiber-tothe-premises (FTTP) solutions [1], [2]. Long-reach access is based on the idea of using a high-capacity, high-split passive optical network (PON), with a reach of $\sim 100 \mathrm{~km}$, to combine optical access and metro into a single system [3]. Systems with symmetric upstream (US) and downstream (DS) data rates of $10 \mathrm{Gbit} / \mathrm{s}$, split factors of 1024 and link lengths up to $135 \mathrm{~km}$ have been reported [1], [3]. These demonstrations, however, make use of advanced schemes such as FEC and EDC [1] and separate fibers and amplifiers for the US and DS signals [1], [3]. We recently proposed a simple, bi-directional, $80 \mathrm{~km}$ PON link based on distributed Raman amplification (DRA) and nonzero dispersion-shifted fiber (NZDSF) [4]. This link design is advantageous since it combines the US and DS signals on a single fiber and features superior noise performance compared to terminal-based amplification, due to the distributed Raman gain. Furthermore, the low dispersion parameter of the NZDSF reduces the need for dispersion compensation.

In this paper, we demonstrate error-free, bidirectional transmission of $10 \mathrm{Gbit} / \mathrm{s} /$ channel across a $120 \mathrm{~km}$ PON link, with no observed penalty due to bi-directionality, with positive net gain for all channels and a received OSNR after transmission in excess of $40 \mathrm{~dB}$. The high on-off gain and good noise performance is obtained using a combined forward and backward pumping scheme and could potentially enable high splitting factors. No dispersion compensation was used.

\section{EXPERIMENTAL SETUP AND RESULTS}

The proposed bidirectional long-reach PON link, along with the surrounding networks, is shown in Fig. 1. The PON link is connected to the metro core node and has a typical length of $\sim 100 \mathrm{~km}$. The link delivers signals to and from the local exchange, where the dense wavelength division multiplexing (DWDM) channels are further distributed to the splitting points at the access part of the network.

The experimental setup is shown in Fig. 2. Two MachZehnder $\mathrm{LiNbO}_{3}$ modulators (MOD) are used to generate the

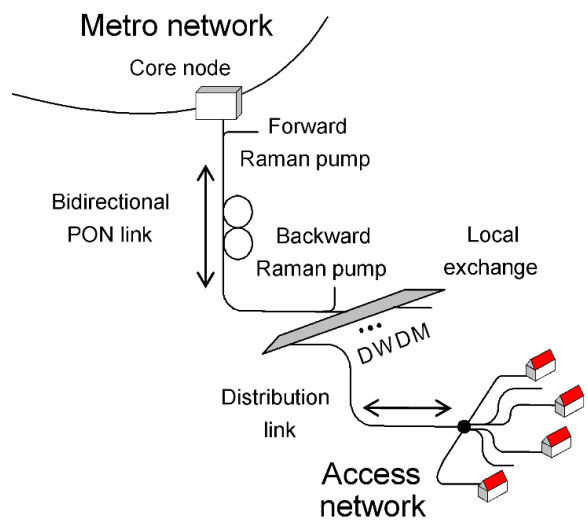

Fig. 1. Extended reach access system based on a single fiber, bidirectional PON link with distributed Raman amplification.

US and DS signals. The electrical signals (a $2^{31}-1$ PRBS pattern) are obtained from the data and inverted data outputs of a pulse pattern generator (PPG). The optical wavelength of the upstream channel is $1548.0 \mathrm{~nm}$ and $1550.4 \mathrm{~nm}$ for the downstream channel. The PON link is composed of $120 \mathrm{~km}$ TrueWave ${ }^{\mathrm{R}} \mathrm{RS}$ with a total passive loss of $24.6 \mathrm{~dB}$ and a total dispersion of $550 \mathrm{ps} / \mathrm{nm}$ at $1550 \mathrm{~nm}$. The employed optical receiver uses no optical pre-amplification.

The upstream and downstream signals are coupled into the PON link using two optical circulators placed at each end of the link. Before transmission, the signals are multiplexed with two co-propagating Raman pumps using a coarse WDM. In this architecture, the signals will see both co- and counterpropagating pumps during transmission. The US and DS signal power into the link (after the WDM) is $-1.3 \mathrm{dBm}$ and -2.3 $\mathrm{dBm}$, respectively. The wavelengths of the upstream pumps are $1437 \mathrm{~nm}$ and $1465 \mathrm{~nm}$ and the optical input powers are 165 $\mathrm{mW}$ and $180 \mathrm{~mW}$. The wavelengths of the downstream pumps are $1427 \mathrm{~nm}$ and $1456 \mathrm{~nm}$ with respective input powers of 231 $\mathrm{mW}$ and $279 \mathrm{~mW}$. At the end of the link, the circulator routes the signal to the receiver, where an optical bandpass filter (BPF) is used to reject the amplified spontaneous emission (ASE) and backscattered power from the counter-propagating channel.

In the bi-directional case, both the US and DS channels are 

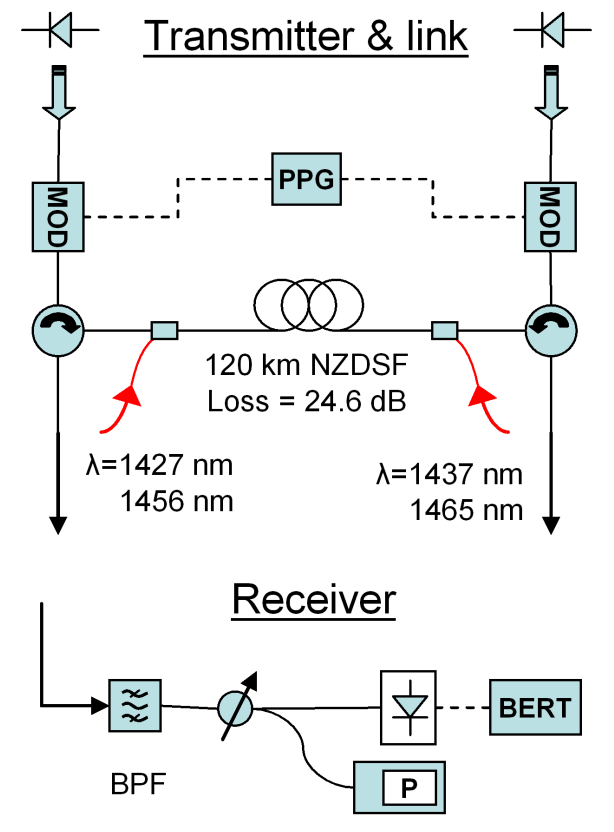

Fig. 2. Experimental setup used to measure the bit-error rate performance of the link.

on and the net gain is measured to $2.9 \mathrm{~dB}$ and $2.2 \mathrm{~dB}$, for those channels, respectively. The corresponding on-off gain is $27.5 \mathrm{~dB}$ and $26.8 \mathrm{~dB}$, which gives rise to a signal power at the output of the link of $1.6 \mathrm{dBm}$ (US) and $-0.1 \mathrm{dBm}$ (DS). The received OSNR (noise spectral density measured in a $0.1 \mathrm{~nm}$ resolution bandwidth) is measured before the BPF and is found to be $40.9 \mathrm{~dB}$ and $41.9 \mathrm{~dB}$ for the US and DS, respectively. With only a single channel turned on (uni-directional case), the gain and OSNR of both channels increased by $0.2 \mathrm{~dB}$, indicating a very low level of gain saturation.

Simulations based on a numerical rate equation model, which includes contributions from ASE noise, backscattering and fiber data of the experimental fiber, was found to agree well with the experimental gain values, with on-off gain values within $1 \mathrm{~dB}$ of the experimental values. We also calculated the level of multi-path-inference (MPI) noise due to doubleRayleigh backscattering (DRB). This effect is known to be a common limitation of high-gain Raman amplifiers. We found the MPI contribution of the system to be less than $-40 \mathrm{~dB}$ for both the US and DS channel, meaning that MPI is not limiting the performance and can be neglected at these pump powers.

Measurements of bit-error-rate (BER) as a function of input power are shown in Fig. 3 for both channels. The channels have been characterized in the case of back-to-back (no transmission), after uni-directional transmission and after bi-directional transmission. The sensitivity is defined as the minimum power at which a BER of $10^{-9}$ can be obtained. We find the back-to-back sensitivities to be $-18.8 \mathrm{dBm}$ and $-19.6 \mathrm{dBm}$, for the US and DS channel, respectively. After unidirectional transmission, we find a sensitivity penalty of $0.8 \mathrm{~dB}$ (US) and $0.9 \mathrm{~dB}$ (DS) and for the bidirectional case,

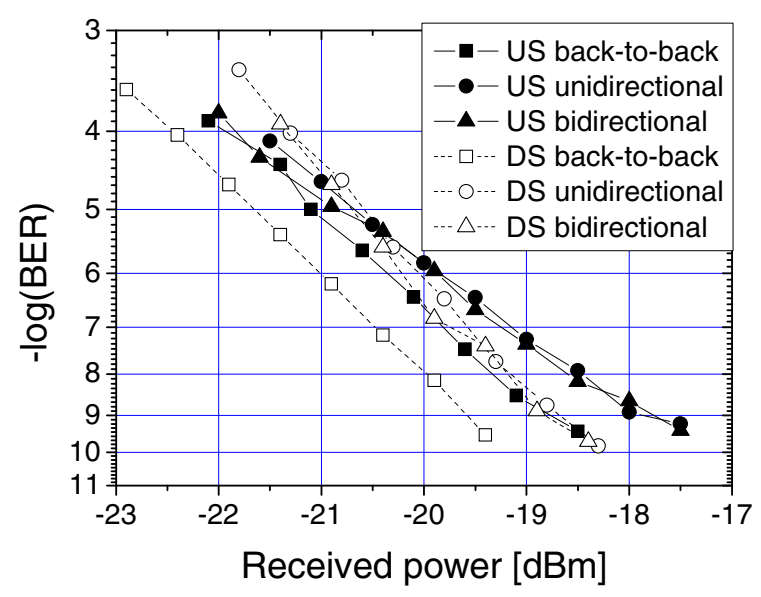

Fig. 3. Bit-error rate as a function of received power for the up- (solid) and downstream (dashed) channels.

the penalty is $0.7 \mathrm{~dB}$ (US) and $0.8 \mathrm{~dB}$ (DS), compared to back-to-back. All in all, penalties of less than $1 \mathrm{~dB}$ are found in all four cases and no performance degradation was found when comparing bi- to uni-directional transmission.

To illustrate the link potential, a power budget for a PON system with $1 / 8$ splitting ratio can be estimated. By assuming a loss of $6 \mathrm{~dB}$ in the local exchange DWDM, a split loss of $9 \mathrm{~dB}$, a combined connector and splice loss of $1.5 \mathrm{~dB}$ and up to $4 \mathrm{~dB}$ of loss due to transmission $(10-20 \mathrm{~km})$ in the access network, the total loss add up to $20.5 \mathrm{~dB}$. With the current output power of $\sim 1 \mathrm{dBm}$ and receiver sensitivity of $-18 \mathrm{dBm}$, a modest increase in gain of 3-6 dB would provide an acceptable power redundancy for practical use. The gain increase could be obtained by a simple increase in the pump powers or signal input power. The power budget shows a clear potential for the DRA-based long-reach PON link, especially for systems with low splitting factors and high capacity.

\section{CONCLUSION}

We have tested a simple design for a long-reach PON link, based on a single bi-directional NZDSF fiber employing distributed Raman amplification. After $120 \mathrm{~km}$ of transmission, without any use of dispersion compensation, we find received OSNR values in excess of $40 \mathrm{~dB}$, transmission penalties limited to $\sim 0.8 \mathrm{~dB}$ and no increased penalty due to the bidirectional operation. To conclude, we find the bidirectional long-reach PON link to be an excellent candidate for future long-reach access systems.

\section{REFERENCES}

[1] D. Nesset et al., "10 Gbit/s Bidirectional Transmission in 1024-way Split, $110 \mathrm{~km}$ Reach, PON System using Commercial Transceiver Modules, Super FEC and EDC," in ECOC 2005, 2005, p. Tu 1.3.1.

[2] T. Koonen, "Fibre-optic techniques for broadband access networks," Telektronikk, vol. 2, pp. 49-65, 2005.

[3] R. Davey et al., "DWDM Reach Extension of a GPON to $135 \mathrm{~km}$," Journal of Lightwave Technology, vol. 24, pp. 29-31, 2006.

[4] I. Tafur Monroy et al., " $10 \mathrm{~Gb} / \mathrm{s}$ bidirectional single fibre long reach PON link with distributed Raman amplification," accepted for publication at ECOC 2006, paper We3.P.166. 